\title{
The Effectiveness Of Daily Assessments: A Preliminary Study In Principles Of Financial Accounting
}

H. Francis Bush, Virginia Military Institute, USA Vonda K. Walsh, Virginia Military Institute, USA

\begin{abstract}
Today colleges and universities are working with students who are younger than the Internet. They were born at the end of the last century, and are referred to as millennials or the Net Generation. Their learning style and time management preferences may respond better to continuous tasks and constant feedback. This paper examines the statistical effects of requiring students to take an assessment as part of their grade in "Principles of Financial Accounting"; specifically, this paper attempts to identify the effects on both student performance and student satisfaction during the semester and at the end of their college career. The increase in students' performances is translated into cost savings for the institution.
\end{abstract}

Keywords: Millennials; Performance; Satisfaction

\section{INTRODUCTION}

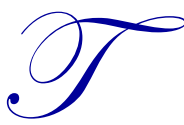

he first "millennials" were born in the early 1980's (Howe \& Strauss, 2003) and they are now the cultural group on campus. Like each preceding group, they bring a different culture and they function differently in society. The millennials, the Net Generation as coined by Tapscott (1998), were born in the nineties and have come to age with the Internet and the War on Terrorism. They live in a world filled with more electronic devices for entertainment and information than any previous generation. They are generally comfortable with technology and have developed different ways to learn and construct communities such as "Facebook" to share and shape their ideas, and ways of learning. The only common trend they have with all previous generations is that they must live and function in the same time frame.

Different students have different strategies for acquiring, organizing, and retaining information, but probably due to their interactions with computers, the millennials are generally better able to integrate visual spatial skills. They have a fast response time and demand a fast turnaround time (Squires et. al., 2008). Textbooks and seminars on educational psychology will frequently address the learning style of the student. Tuckman (1992) states that "Quite apart from the question of a person's intelligence is the question of how the person typically goes about thinking and learning" (p. 350). Different generations come of age at different moments in history, bringing with them their own perspectives and needs.

According to Howe and Straus (2003) the millennials have a wide range of characteristics which impact their experiences. They enjoy a close tie to their parents. Millennials are more interested in extracurricular activities and community services. They have developed a greater expertise with technology and they prefer a more secure and regulated environment. They are "extremely focused on grades and performance." These characteristics and the educational program which the millennials experience before starting college may have changed their focus from process to outcome. All too often a student perceives that time spent studying should cause a certain grade. The focus is more on grade/outcome than the learning process. Consequently, students in principles of financial accounting recently were required to complete daily assessments of which more were open book than closed book in lieu of daily homework assignments. 
Specially, Howe and Straus have identified several traits among new millennial which directly impact their classroom performance. The new millennials are "special." They suggest that today's college students expect to be monitored regularly and to receive frequent feedback/praise related to their performance. "For all students, the key is feedback and structure" (p. 46). They preferred to work in groups on short-term projects. Assessments which allow small groups of students to work together will provide more motivation and learning. The new millennials feel a greater need to organize the enormous amount of information available to them for any course. Finally, they are "pressured" and "achieving." "Pushed to study hard, avoid personal risks, and take full advantage of the collective opportunities that adults are offering them, Millennials feel a 'trophy kid' pressure to excel" (p. 31). To better suit these traits and needs, daily homework assignments were replaced with daily assessments; these often allowed for collaborative efforts but a significant minority of the assessments were "individual quizzes."

Further, the research of Michaels and Miethe (1989) demonstrated that academic effort has a significant effect on college grades. Using undergraduate students enrolled in courses that fulfilled general educational requirements, Michaels and Miethe conducted a survey related to grades and study habits. They reported that study time had a significant impact on grades while class attendance did not. Their results also indicated that "class attendance and amount of study are associated with higher grades for those who study throughout the week, but not for "crammers"' (p. 317). Activities, that require students to study throughout the week, should produce a more constant effort of the student's part as well as provide more opportunities for feedback, and will likely result in better learning.

Finally, the improved learning should result in higher grades. Higher grades should increase the satisfaction levels of the millennials. Their satisfaction should in turn increase teachers' rating on the semester's course evaluation.

The purpose of this research is to examine the immediate effects of replacing daily homework assignments with assessments, prepared collaboratively and individually. More specifically we will test the following four hypotheses:

$\mathbf{H}_{1}$ : $\quad$ Students who take daily assessments will earn higher grades;

$\mathbf{H}_{2}$ : $\quad$ Students who take daily assessments will outperform other students on the final exam;

$\mathbf{H}_{3}$ : Students who take daily assessments will outperform other students on the major field exam in business, and

$\mathbf{H}_{4}$ : $\quad$ Students who take daily assessments will report higher satisfaction in course evaluations.

\section{METHODS}

The study involved 52 students enrolled in Principles of Financial Accounting; this represented the entire enrollment of a small Economics and Business program. The control group was the students from the previous three years. A three year period was chosen for the control group because it provides a significant base line and should minimize the effects of changes from year to year. The subjects were simply told that the homework portion of the course grade had been replaced by daily assessments. These assessments were approximately 25 percent closed book and 75 percent open book.

Replacing homework with daily assessments was the only change in the structure of the course from the prior three years. The assessments were developed during the summer and followed the previously developed lectures. As the school has a single sanction honor code (any student convicted of academic dishonesty is dismissed), the assessments were made available on the faculty member's door. This approach is the norm for the school. Further, the distribution of grades indicated that the integrity of the assessment scores had been maintained. Methods for managing the daily assessment for different academic operating constraints will be discussed below.

Each hypothesis had its own measurements. Performance in the course was measured based on the assigned course grade and the percentage of students who received a satisfactory grade (a grade which would not require them to repeat the course). Performance on the final was based on the average percentage grade on each topic of the final exam. Performance on the major field exam in business was measured by the accounting section percentile score. Students' satisfaction was based on scores on the course evaluation at the end of the semester. 
The collected data were analyzed using descriptive statistics. Independent sample t-tests were performed for comparing mean scores for each section of the final exam, while Chi-square and Likelihood Ratio tests were performed to investigate possible differences in assigned letter grades. Statistical calculations were performed with the assistance of SPSS ${ }^{\circledR}$ software for Windows. All student records were keep locked away and could only be assessed by the authors.

\section{RESULTS}

\section{Performance as Measured in Grades}

Results from the experiment are shown in Tables 1 through 4 and Figures 1 through 3. Table 1 and Figure 1 represent the relationship between the performances of the experimental group using daily assessment versus the control group, the previous three year population of grades earned. The first hypothesis predicts that higher grades will be earned in the experimental group. The grade distributions for both groups are presented in Table 1.

A review of these results indicates that the students earned higher grades when using the daily assessments. In the highest three grade (A, B, and C), not only did the cumulative percentages of the experimental group outpace the grades earned by the control groups, there actually was a higher percentage in each of the categories. Consequently there are lower percentages of students earning grades of $\mathrm{D}, \mathrm{F}$, and $\mathrm{W}$ for students using daily assessments. Although, the grade distribution is consistent with the alternative hypothesis, neither the Pearson ChiSquare nor the Likelihood Ratio statistics were significant at traditional levels. The Likelihood Ratio test was performed because several cells did not have a sufficient number of observations, 5.38.

Table 1: Grade Distributions

\begin{tabular}{|l|c|c|c|c|}
\hline & \multicolumn{2}{|c|}{ Without Daily Assessments } & \multicolumn{2}{c|}{ With Daily Assessments } \\
\hline Quantity & $\begin{array}{c}\text { Percentage } \\
\text { (Cumulative Percentage) }\end{array}$ & Quantity & $\begin{array}{c}\text { Percentage } \\
\text { (Cumulative Percentage) }\end{array}$ \\
\hline A & 15 & $9.9(9.9)$ & 6 & $11.5(11.5)$ \\
\hline B & 37 & $24.5(34.4)$ & 15 & $28.8(40.3)$ \\
\hline C & 54 & $35.8(70.2)$ & 22 & $42.3(82.6)$ \\
\hline D & 16 & $10.6(80.8)$ & 1 & $1.9(84.5)$ \\
\hline F & 8 & $5.3(86.1)$ & 0 & $0(84.5)$ \\
\hline W & 21 & $13.9(100.0)$ & 8 & $15.4(99.9)$ \\
\hline Total & 151 & $100 \%$ & 52 & $100 \%$ \\
\hline
\end{tabular}

Another measure of performance is satisfactory versus unsatisfactory performance. The minimum required grade for graduation requirements in Principles of Financial Accounting varies from programs; generally some programs require a "C," while other programs simply require a " $\mathrm{D}$ " in Principles of Financial Accounting. Using either a cutoff based on "C" or " $\mathrm{D}$," students using daily assessment outperform students who do not. Figure 1 is a graphical representation using " $\mathrm{C}$ " as the cutoff and Figure 2 is a graphical representation using " $\mathrm{D}$ " as the cutoff. It should be noted that generally a grade of "C" is required to gain transfer credit at another school.

The grade of "W" represents students who withdraw from the class and this leaves some room for interpretation as this grade cannot be assumed to represent a performance value in either category; however, the grade is often associated with students receiving D or F. Occasionally, students realized that for personal reason, they no longer need the course to graduate and leave the course. This later group will not be returning to re-take the course and cause no additional cost to the department. The "W" in either interpretation is unsatisfactory. 


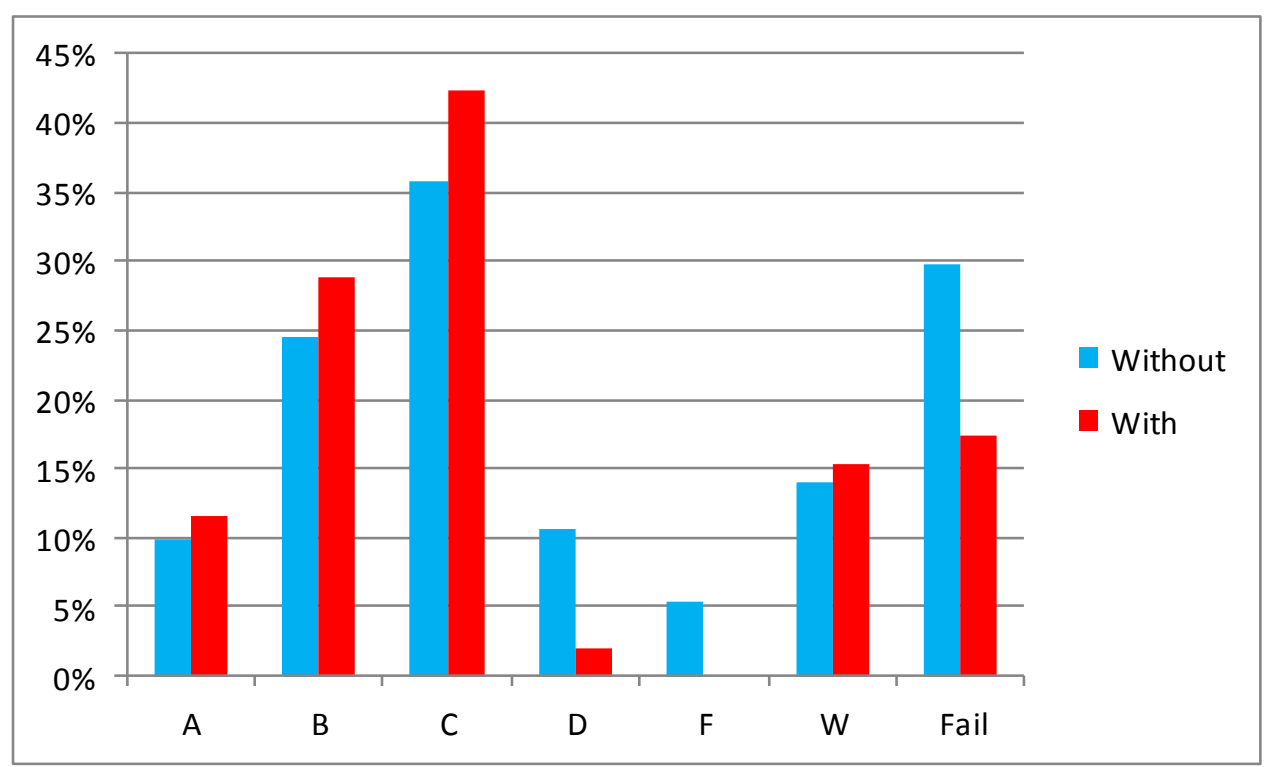

Figure 1: Grade Distributions where Fail is Any Grade Below C

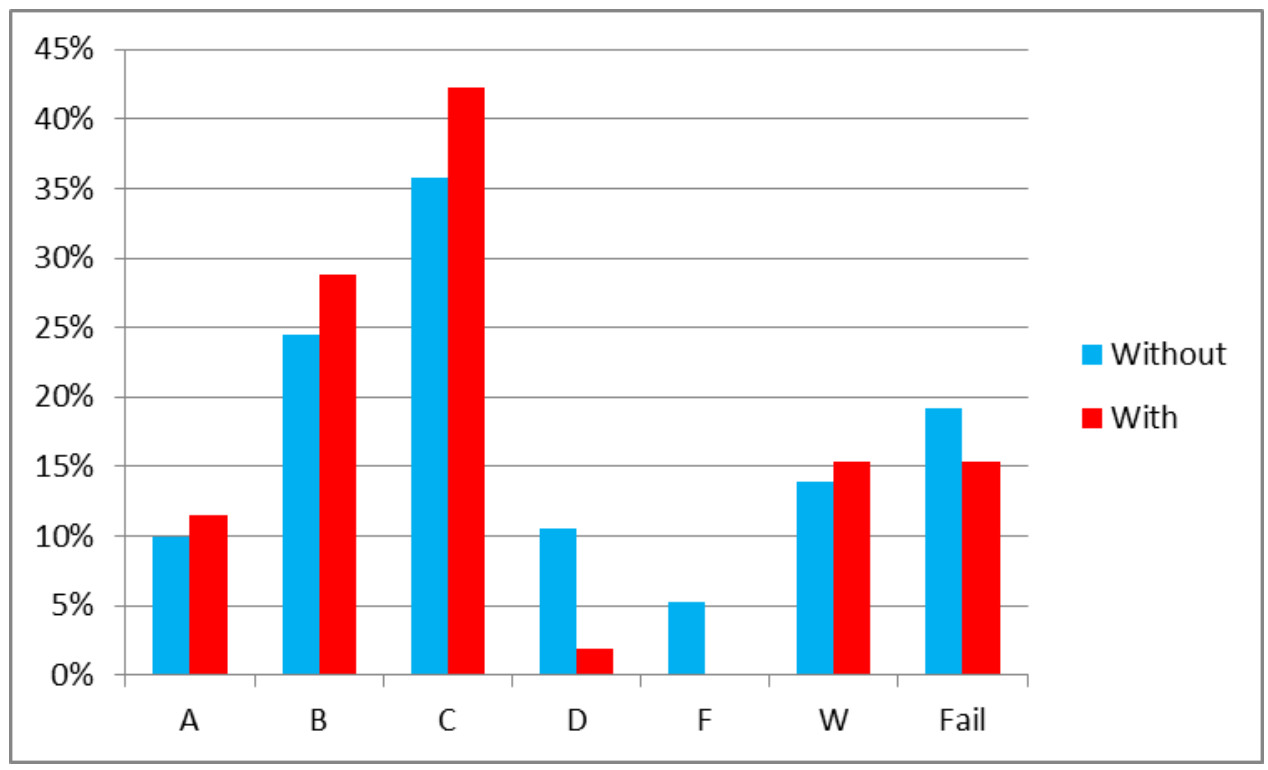

Figure 2: Grade Distributions where Fail is Any Grade Below D

Students who took daily assessment were more likely to earn a satisfactory score in Principles of Financial Accounting. Using the grades of A, B, and C as satisfactory grades, only 70.2 percent successfully completely the course without the assessment, while 82.7 percent successfully completed the course with the assessments. Using the grades of A, B, C, and D as satisfactory grades, only 80.8 percent successfully completely the course without the assessment, while 84.6 percent successfully completed the course with the assessments. Additionally, we classify a grade of $\mathrm{C}$ or better as minimally proficient in the subject area and all other grades to include $\mathrm{W}$ as not proficient. The Pearson Chi-Square was significant at p-value < 0.040 and the Likelihood Ratio was significant at p-value < 0.035. The Likelihood Ratio test was performed because several cells did not have a sufficient number of observations, 13.83 .

Finally, the grade of "W" offers an interesting contradiction. Students who were required to take daily assessments were more likely to withdraw from class than those who simply did homework problems. Although exit surveys were not used for the students who withdrew, there was antidotal evidence that most of these students 
had decided to switch majors. It is possible that daily assessment provided earlier feedback to the students about their performance, and that they made their decision on a timelier basis.

\section{Performance as Measured on the Final}

Generally, the final exam is a significant portion of the final grade. The final represented thirty percent of the final grade for these students. Consequently, the second hypothesis indicates that the performance on the final will be stronger for the students who received daily assessments. However, an examination of the students' performance allows a closer examination on various topics and the ability of students to retain information. Table 2 summarizes the average percent correct on each section of the final exam in Fall of 2008, without daily assessments, and 2009, with daily assessment. There were 44 students who completed the course in 2008. In this comparison, previous years were not considered because certain polices related to the final exam had changed in 2008 . We noted significant difference in performance (p-value < 0.05) for subtopics Adjusting Entries, Time Value of Money and Bonds, Stockholders' Equity, Bank Reconciliation, and Inventory, with daily assessment students obtaining scores significantly greater than the non-daily assessment students for each of these subtopics. There was no significant difference in performance in the remaining subtopics: Cash Flow Statement, Depreciation, and Ratios.

Table 2: Average Final Scoresby Topic

\begin{tabular}{|l|c|c|c|c|}
\hline \multicolumn{1}{|c}{ Topic } & \multirow{2}{*}{ Without } & \multirow{2}{*}{ With } & \multicolumn{2}{c|}{ p-value for Equality of Means } \\
\cline { 5 - 5 } & & & Equal Variances & Unequal Variances $^{\mathbf{1}}$ \\
\hline Adjusting Entries & $34.4 \%$ & $64.2 \%$ & 0.000 & 0.000 \\
\hline Cash Flow Statement & $71.4 \%$ & $72.3 \%$ & not significant & not significant \\
\hline Time Value of Money and Bonds & $67.6 \%$ & $82.9 \%$ & 0.002 & 0.002 \\
\hline Stockholders' Equity & $59.6 \%$ & $79.3 \%$ & 0.000 & 0.000 \\
\hline Bank Reconciliation & $57.6 \%$ & $86.3 \%$ & 0.000 & 0.000 \\
\hline Inventory $^{\text {Depreciation }}{ }^{2}$ & $73.8 \%$ & $86.9 \%$ & 0.001 & 0.001 \\
\hline Ratios $^{3}$ & $80.2 \%$ & $76.1 \%$ & not significant & not significant \\
\hline
\end{tabular}

Although, the results in general support the second hypotheses, there were some notable exceptions. As shown in Figure 3, students who received daily assessments performed significantly better in five of the eight areas on the final - adjusting entries, time value of money and bonds, stockholders' equity, bank reconciliation, and inventory methods. The performance on the cash flow statement was approximately the same. Depreciation and ratios were the exceptions. Students who did not received daily assessments performed better on these topics. Ratios are not covered as a unit and were not necessarily emphasized on the assessments. Depreciation is the final unit of the course. The difference is less than five percent which might be a random observation or the students could have reached their limit for acquiring and retaining information from their work on the earlier material. Further research could investigate this issue. Overall, students who took daily assessments were better able to retain information for the semester.

\footnotetext{
${ }^{1}$ Levene's Test for Equality of Variances was applied to the data. The equality of the variances was rejected for cash flow statement and depreciation data. However, the results under either assumption do not differ.

${ }^{2}$ Deprecation is the last topic covered during the semester. The last exam takes place at the end of the term and the final again a few days later.

${ }^{3}$ Ratios are covered at various points during the semesters. Generally they are associated with the actual preparation of financial statements which is not specifically covered on the final exam.
} 


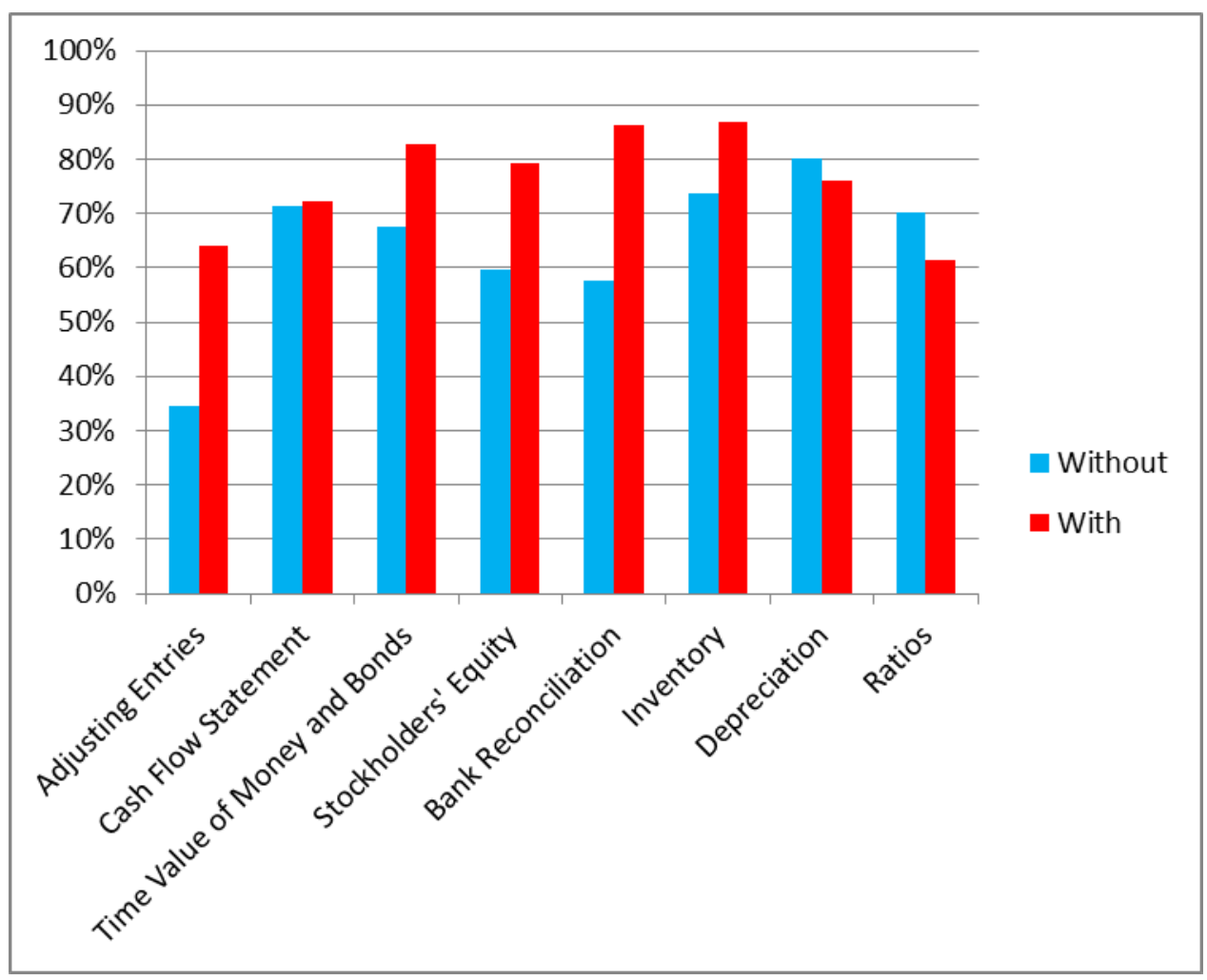

Figure 3: Average Final Scoresby Topic

\section{Performance as Measured on the Major Field Test in Business (MFTB)}

The last aspect of performance is long-term retention. The institution has administered the Educational Testing Service's (ETS) major field test in business as part of the assessment of the academic program in economic and business. The results are presented in Table 3. Although the results since implementing the daily assessments do not indicate any significant increase in the performance on the accounting section of the MFTB, the performance has remained reasonably stable. This is in contrast with the decline in the overall performance.

Table 3: Students Performance on the MFTB

\begin{tabular}{|l|c|c|c|c|c|}
\hline \multicolumn{1}{|c|}{ MFTB Area } & Without Daily Assessments & \multicolumn{3}{|c|}{ With Daily Assessments } & \\
\hline Year & 2010 & 2011 & 2012 & 2013 & $11-13$ Average \\
\hline Accounting & $45^{\text {th }}$ & $45^{\text {th }}$ & $41^{\text {st }}$ & $45^{\text {th }}$ & $43.7^{\text {th }}$ \\
\hline Overall Score & $85^{\text {th }}$ & $83^{\text {rd }}$ & $65^{\text {th }}$ & $76^{\text {th }}$ & $74.7^{\text {th }}$ \\
\hline
\end{tabular}

\section{Satisfaction as Measured on Course Evaluations}

Generally at the end of the semester students are asked to complete course evaluations. The course evaluation for Principles of Financial Accounting had two questions related to the use of assessments. First, students are asked to respond to the following statement "The instructor demonstrated interest in my success in this course." This question is the closest measure to student satisfaction. It appears that the students were less satisfied when receiving daily assessments. The results are presented in Table 4.

Although, the professor's evaluations were still strong, there was a slight decline in the percentage of students who "strongly agreed" with the statement. However, it should be noted that significantly more students withdrew from the course when assessments were used which might have had higher level of dissatisfaction, a point for further research. 
Table 4: Students Ranking of Instructor's Interest in their Success

\begin{tabular}{|l|c|c|c|c|c|c|}
\hline \multicolumn{1}{|c|}{ Student Ranking } & Strongly Agree & Agree & Neutral & Disagree & Strongly Disagree & Total \\
\hline \multirow{2}{*}{ With (proportion) } & 30 & 7 & 1 & 2 & 0 & 40 \\
& $(0.750)$ & $(0.175)$ & $(0.025)$ & $(0.050)$ & $(0.000)$ & $(1.000)$ \\
\hline \multirow{2}{*}{ Without (proportion) } & 38 & 2 & 3 & 0 & 0 & 43 \\
& $(0.884)$ & $(0.046)$ & $(0.070)$ & $(0.000)$ & $(0.000)$ & $(1.000)$ \\
\hline Without & 38 & 2 & 3 & 0 & 0 & 43 \\
\hline
\end{tabular}

Another measure of student satisfaction was available on the course evaluations. Students were asked to respond to the following questions in a single provided space: "What course activity provided the most intellectual simulation?" "Which was lest stimulating?" Although a comparison with the previous year is not possible because the earlier class did not have the option of daily assessments, the result for the semester in which the daily assessments were used provides the following:

- $\quad$ Thirty percent of the students left this question blank.

- $\quad$ Forty-two and a half percent did not address the daily assessment in their comments.

- Those who commented on daily assessments favored the assessment in approximately a three-to-one ratio.

Therefore it appears that students' reactions to daily assessment would best be described as mixed.

\section{CONCLUSIONS AND FUTURE CONSIDERATIONS}

Results demonstrate that students, on average, perform better when they are required to do daily assessments as opposed to completing homework assignments. These improvements come with mixed effects on student evaluations of faculty. Measures of performance, course grades, and final exam scores are stronger for students who received daily assessments. Performance on the individual section of the final exam indicate that students appear to have greater retention. Performance on the course grade and passing rates are driven in part by the improved performance on the final as well as improved performance on the individual exams. It should be noted that the course grade is also composed of average assessment scores which were significantly lower than homework scores. Although there is some contradictory evidence, in terms of satisfaction, students appeared to slightly lower their assessment of the instructor when required to complete daily assessments.

There are three limitations to this study that should be discussed, the decline in student evaluation of faculty, the lack of tests on the effects on long-term retention, and the nature of the teaching environment. The first point is perhaps one of institutional choice. The increase in performance has provided a decline in seats in excess of fifteen percent, which has significant budget impacts on class size. This positive effect as well as the impact of students' performance should improve the faculty member's overall evaluation. The second point was tested when these students take their field exams as seniors. Although, the results were not significant, the results indicated more retention in accounting than other areas tested by the major field exam in business. The third point is more difficult. The school is a small liberal arts school having 50 to 60 majors per year, one professor and three sections of approximately 20 to 25 students per year. Not every institution has these parameters.

An additional concern arises from the experimental design itself. Given the limited number of students, and the close nature of the student body, it would have been difficult to have both the control group and the experimental group in the same semester. The school has mandatory residence in a single large structure for all students. Even though we have a fairly homogeneous student body, the possibility exists that the experimental group was more academically advanced than the control group.

In effort to determine if there is a difference in the educational background of the two groups, an independent sample t-test was performed on the students' graduating GPA, which failed to reject the null hypotheses at a p-value less than 0.10. Another indication that the experimental group is not academically stronger is in the data on the MFTB. On average students in the control group would have taken the MFTB in 2010 and 2011, while the students in the experimental group would have on average taken the MFTB in 2012. The scores in 2012 were actually below average indicating lesser abilities in the business areas in general for the students in the experimental 
group. Further, the decline in performance was not as severe among the accounting scores (See Table 3). Although the results described above are consistent with the hypothesis that students in the experimental group are not more academically advance, future research will need to specifically control for the inherent abilities of members in each group.

Although it is beyond the scope of this paper, daily assessment can be applied in various environments with creative planning. For example, an extreme opposite instructional environment would be a large state, research oriented university in which the Principles of Financial Accounting is coordinated by a senior faculty and handled by numerous doctoral students. In this environment, the doctoral students could simply maintain a testing room where student's identification could be managed and the assessment scored. Another approach could put the assessments on line. This approach may limit the use of partial credit. Each program adopting daily assessments would have to determine the specifics of the applications, with each activity focused on student-centered learning with appropriate technological tools. However, the cost savings in terms of resources makes the option most deserving of consideration.

\section{AUTHOR INFORMATION}

Dr. H. Francis Bush is a Professor of Economics and Business at the Virginia Military Institute. He received a B.A. in Mathematics from the State University of New York at Buffalo, NY, his Masters of Accountancy from The Ohio State University and his PhD from the University of Florida. E-mail: bushhf@vmi.edu (Corresponding author)

Dr. Vonda K. Walsh is a Professor of Applied Mathematics at Virginia Military Institute. She received her B.S. in Mathematics from the University of Virginia's College at Wise, her M.S. in Pure Mathematics from Virginia Tech and her Ph.D. in Biostatistics from the Medical College of Virginia/Virginia Commonwealth University School of Medicine. E-mail: Walshvk@vmi.edu

\section{REFERENCES}

1. Howe, N., \& Strauss, W. (2000). Millennials rising the next generation. Vintage Books.

2. Howe, N., \& Strauss, W. (2003). Millennials go to college. Life Course Associates.

3. Michaels, J. W., \& Miethe, T. D. (1989). Academic effort and college grade. Social Forces, 68(1), 309-19.

4. Tapscott, D. (1998). Growing up digital: The rise of the net generation. McGraw-Hill Companies.

5. Tuckman, B. W. (1992). Educational psychology from theory to application. Harcourt Brace Jovanovich. Orlando, Florida.

6. Squire, J. C., Bush, H. F., Walsh, V. K., Sullivan, G. A. W., \& English, A. (2008). Results for a multicenter investigation of the effects of network latency on pedagogic efficacy. Computers in Education Journal, $18(1), 103-12$. 